\title{
Depth of formation of super-deep diamonds
}

\author{
Anzolini C. ${ }^{1, *}$, Nestola F. ${ }^{1}$ and Harris J.W. ${ }^{2}$ \\ ${ }^{1}$ University of Padova, Padova, Italy, chiara.anzolini@phd.unipd.it, fabrizio.nestola@unipd.it \\ ${ }^{2}$ University of Glasgow, Glasgow, United Kingdom, Jeff.Harris@glasgow.ac.uk
}

\section{Introduction}

Diamonds and the mineral inclusions that they trap during growth provide a unique window on the deep Earth. A small portion ( $6 \%$ ) of diamonds (Stachel and Harris 2008) are interpreted to crystallize between 300 and $800 \mathrm{~km}$ depth (Harte 2010) because some of the inclusions entrapped are considered to be the products of retrograde transformation from lower-mantle or transition-zone precursors. However, in many cases undisputed evidence of these purported high-pressure precursors as inclusions in diamonds is lacking, and, consequently, their real depth of origin has been proven only in rare cases (e.g. Brenker et al. 2002; Pearson et al. 2014). Most so-called "super-deep diamonds" contain mainly walstromite-structured $\mathrm{CaSiO}_{3}\left(\mathrm{CaSiO}_{3}\right.$-walstromite $)$, ferropericlase $\left.((\mathrm{Fe}, \mathrm{Mg}) \mathrm{O})\right)$, enstatite $\left(\mathrm{MgSiO}_{3}\right)$ and jeffbenite $\left((\mathrm{Mg}, \mathrm{Fe})_{3} \mathrm{Al}_{2} \mathrm{Si}_{3} \mathrm{O}_{12}\right)$, and it is through the study of these mineral phases that the depth of formation of super-deep diamonds can be retrieved.

$\mathrm{CaSiO}_{3}$-walstromite is a dominant Ca-bearing phase in super-deep diamonds (Joswig et al. 1999) and it has been suggested that it is the product of back transformation from $\mathrm{CaSiO}_{3}$ - perovskite, which is stable only below $\sim 600 \mathrm{~km}$ depth. Nevertheless, its real depth of origin is controversial. Single-inclusion elastic barometry, a method recently improved by Angel et al. $(2014,2015)$, allows us to estimate the pressure and temperature conditions of entrapment for an inclusion within a diamond by knowing its residual pressure $\left(P_{\text {inc }}\right)$, measured at ambient conditions, and the thermoelastic parameters of the mineral inclusion and the diamond host. The $P_{\text {inc }}$ sustained by an inclusion can be determined mainly in two ways: 1) by comparing the unit-cell volume of the inclusion before and after release from its host; 2) by comparing the Raman spectrum of the inclusion still trapped within the diamond and the Raman spectrum of the same mineral phase at room pressure. The first method requires inclusions large enough to be analyzed by single-crystal X-ray diffraction, but large inclusions are more likely to fracture the surrounding host during exhumation and therefore their internal pressure is largely released. The second method allows the analysis of tiny inclusions with no fractures in the diamond host, which commonly preserve higher internal pressures, and, at the same time, the original integrity of the host-inclusion system is maintained.

This work aims to obtain the depths of formation of diamonds containing $\mathrm{CaSiO}_{3}$-walstromite inclusions by non-destructive methods. At present, we have studied 6 super-deep diamonds by a combination of in situ single-crystal X-ray diffraction and micro-Raman spectroscopy. High-pressure micro-Raman investigations were carried out to obtain a calibration curve to determine the $P_{\text {inc }}$ of a $\mathrm{CaSiO}_{3}$-walstromite inclusion by means of Raman spectroscopy without breaking the diamond. We additionally calculated the Raman spectrum of $\mathrm{CaSiO}_{3}$-walstromite by ab initio methods both under hydrostatic and non-hydrostatic stress conditions to avoid misinterpretation of the results caused by the possible presence of deviatoric stresses causing anomalous shift of $\mathrm{CaSiO}_{3}$-walstromite Raman peaks. Lastly, we applied single-inclusion elastic barometry to estimate the entrapment pressure of $\mathrm{a} \mathrm{CaSiO}_{3}$ walstromite-diamond pair.

\section{Experimental Methods}

X-ray data were collected in situ on the inclusions using a a Rigaku Oxford Diffraction SuperNova goniometer, equipped with a Dectris Pilatus $200 \mathrm{~K}$ area detector and with a Mova X-ray microsource. A MoKa radiation was operated at $50 \mathrm{kV}$ and $0.8 \mathrm{~mA}$. The sample to detector distance was $68 \mathrm{~mm}$. Data reduction was performed using CrysAlis software (Rigaku Oxford Diffraction), which corrected for Lp 
effects and absorption. Raman measurements were carried out in situ with a Thermo Scientific ${ }^{\mathrm{TM}}$ DXR Raman Microscope using a green argon ion laser $(532 \mathrm{~nm})$ as excitation source at the Department of Geosciences, University of Padova. The analyses were performed using a $50 \times$ objective with $\sim 2.5 \mathrm{~cm}^{-}$ ${ }^{1}$ spectral resolution and $1.1 \mu \mathrm{m}$ spatial resolution at $10 \mathrm{~mW}$ of power. The synthetic $\mathrm{CaSiO}_{3}$ walstromite crystal selected for the Raman investigation was synthesized at $9 \mathrm{GPa}$ and $2000 \mathrm{~K}$ in a multi-anvil press. First, a Raman spectrum was collected at room conditions; for the high-pressure measurements a diamond-anvil cell was loaded with the crystal of $\mathrm{CaSiO}_{3}$-walstromite, a piece of ruby as internal pressure standard and a 4:1 mixture of methanol:ethanol as pressure- transmitting medium. The Raman spectra were collected at the University of Roma Tre with a micro-Raman spectrometer equipped with a green argon ion laser $(532 \mathrm{~nm})$ focused through a $20 \times$ LWD objective. The spatial resolution of the sample surface was $\sim 1 \mu \mathrm{m}$ and the spectral resolution was $0.3 \mathrm{~cm}^{-1}$. Spectral fitting was carried out using the Thermo Scientific ${ }^{\mathrm{TM}}$ OMNIC ${ }^{\mathrm{TM}}$ Spectra Software. The ab initio calculation of the vibrational frequencies and intensities of the Raman-active modes was performed by using the CRYSTAL14 software (Dovesi et al. 2013).

\section{Analytical Results}

At ambient pressure the main Raman peaks of $\mathrm{CaSiO}_{3}$-walstromite were observed at 656, 977 and 1037 $\mathrm{cm}^{-1}$ (hereafter called Peak 1, 2 and 3, respectively). With increasing pressure, all Raman peaks shifted continuously toward higher wavenumbers. In particular, Peaks 1 and 2 showed almost linear trends. The pressure-dependence of the three main Raman bands was fitted with a weighted linear regression and the resulting pressure coefficients were: $\mathrm{d} v / \mathrm{d} P=3.22(5) \mathrm{cm}^{-1} \mathrm{GPa}^{-1}$ for Peak $1, \mathrm{~d} v / \mathrm{d} P=5.16(9)$ $\mathrm{cm}^{-1} \mathrm{GPa}^{-1}$ for Peak 2 and $\mathrm{d} v / \mathrm{d} P=6.5(1) \mathrm{cm}^{-1} \mathrm{GPa}^{-1}$ for Peak 3 (Figure 1a). Our calculated Raman spectra under hydrostatic stress are comparable with the experimental frequencies. Again, all Raman frequencies systematically increase with increasing pressure. The pressure-dependence of the three main Raman bands was fitted with a weighted linear regression and the resulting pressure coefficients were: $\mathrm{d} v / \mathrm{d} P=3.32 \mathrm{~cm}^{-1} \mathrm{GPa}^{-1}$ for Peak $1, \mathrm{~d} v / \mathrm{d} P=4.68 \mathrm{~cm}^{-1} \mathrm{GPa}^{-1}$ for Peak 2 and $\mathrm{d} v / \mathrm{d} P=5.89 \mathrm{~cm}^{-1}$ $\mathrm{GPa}^{-1}$ for Peak 3 (Figure 1b). The ab initio calculated peak shifts under non-hydrostatic stresses show patterns similar to those under hydrostatic pressure. Also, the pressure-dependencies of the three main peaks under non-hydrostatic stresses are comparable to those calculated under hydrostatic pressure. However, Peak 2 is the least sensitive to the application of differential stresses, and therefore it is the most reliable peak to be used as a calibrant to calculate the $P_{\text {inc }}$ of a $\mathrm{CaSiO}_{3}$-walstromite inclusion.Therefore, we used its pressure coefficient to calculate the $P_{\text {inc }}$ of an inclusion still trapped within a diamond which shows the highest Raman peak shifts ever reported in the literature (main Raman peaks at 669,999 and $1061 \mathrm{~cm}^{-1}$ ) and we obtained a value of 4.26(7) $\mathrm{GPa}$.
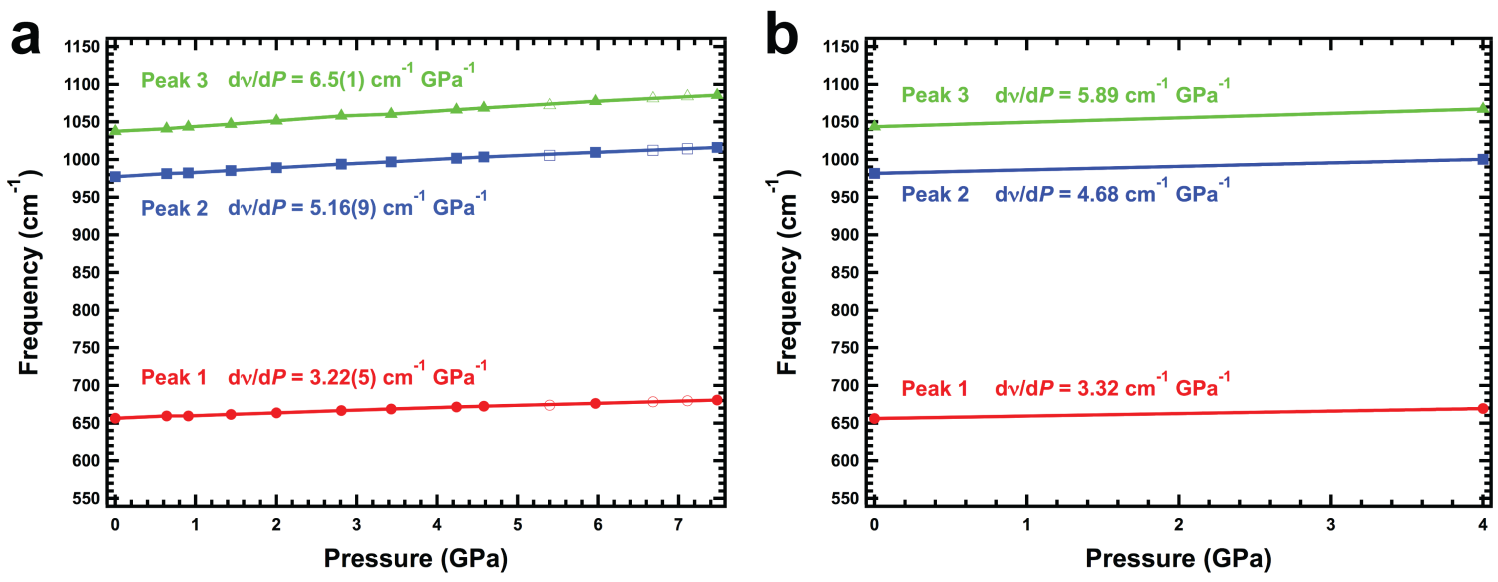

Figure 1: a) Experimental and b) calculated pressure dependencies of the main Raman peaks of $\mathrm{CaSiO}_{3}$ walstromite under hydrostatic conditions. In a) compression and decompression are represented by solid and open symbols, respectively. The error bars lie within the symbols. 
Ten $\mathrm{CaSiO}_{3}$-walstromite inclusions were individually investigated by single-crystal X-ray diffraction. All of the inclusions have unit-cell volumes less than the room pressure volume of $\mathrm{CaSiO}_{3}$-walstromite $\left(\sim 376 \AA^{3}\right)$, confirming the Raman results that these inclusions retain a remnant pressure. We have determined their residual pressures, which range from $\sim 0.17$ to $\sim 1.8 \mathrm{GPa}$, by using the thermoelastic parameters for $\mathrm{CaSiO}_{3}$ walstromite reported in Anzolini et al. (2016). The presence of fractures around these inclusions explains why they exhibit lower pressure than the residual pressure of 4.26(7) GPa obtained previously by using the Raman calibration curve.

The calculation of the pressure of formation for the $\mathrm{CaSiO}_{3}$-walstromite - diamond pair was performed with the software EoSFit7c. We used thermal expansion and compressibility data for $\mathrm{CaSiO}_{3}$ walstromite reported in Anzolini et al. (2016), thermoelastic properties for diamond from the review of Angel et al. (2015) and the residual pressure of 4.26(7) $\mathrm{GPa}$. Assuming a temperature range between $1200 \mathrm{~K}$ and $2000 \mathrm{~K}$ for $\mathrm{CaSiO}_{3}$ -

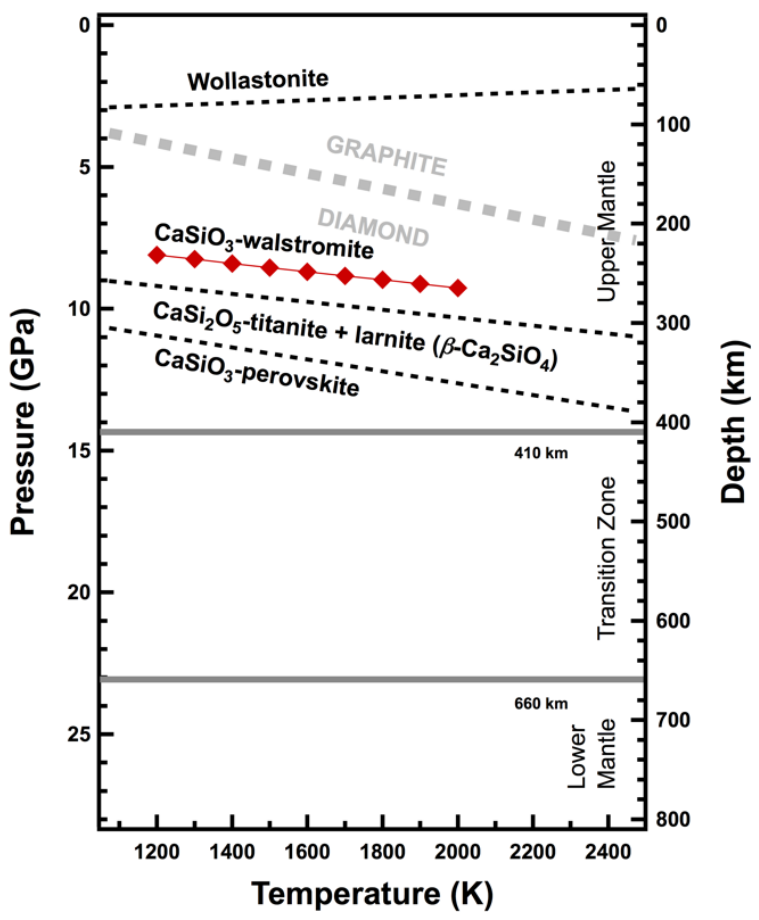

Figure 2: Phase diagram of the $\mathrm{CaSiO}_{3}$ system. Entrapment pressures from which our sample may have originated are represented with red symbols. walstromite formation, we obtained entrapment pressures ranging from 8.10 to $9.27 \mathrm{GPa}$, corresponding to 240-280 km depth (Figure 2, from Anzolini et al. 2017).

\section{References}

Angel RJ, Mazzucchelli ML, Alvaro M, Nimis P, Nestola F (2014) Geobarometry from host-inclusion systems: The role of elastic relaxation. Am Mineral 99:2146-2149

Angel RJ, Alvaro M, Nestola F, Mazzucchelli ML (2015) Diamond thermoelastic properties and implications for determining the pressure of formation of diamond-inclusion systems. Russ Geol Geophys 56:211-220

Anzolini C, Angel RJ, Merlini M, Derzsi M, Tokár K, Milani S, Krebs MY, Brenker FE, Nestola F, Harris JW (2016) Depth of formation of $\mathrm{CaSiO}_{3}$-walstromite included in super-deep diamonds. Lithos 265:138-147

Anzolini C, Prencipe M, Alvaro M, Romano C, Vona A, Lorenzon S, Smith EM, Brenker FE, Nestola F (2017) Depth of formation of super-deep diamonds: Raman barometry of $\mathrm{CaSiO}_{3}$-walstromite inclusions. Am Mineral submitted

Brenker FE, Stachel T, Harris JW (2002) Exhumation of lower mantle inclusions in diamond: A TEM investigation of retrograde phase transitions, reactions and exsolution. Earth Planet Sci Lett 198:19

Dovesi R, Saunders V, Roetti C, Orlando R, Zicovich-Wilson C, Pascale F, Civalleri B, Doll K, Harrison N, Bush I CRYSTAL14 User's Manual; University of Torino: Torino, 2014

Harte B (2010) Diamond formation in the deep mantle: the record of mineral inclusions and their distribution in relation to mantle dehydration zones. Mineralogical Magazine 74:189-215

Joswig W, Stachel T, Harris JW, Baur WH, Brey GP (1999) New Ca-silicate inclusions in diamonds tracers from the lower mantle. Earth Planet Sci Lett 173:1-6

Pearson D, Brenker F, Nestola F, McNeill J, Nasdala L, Hutchison M, Matveev S, Mather K, Silversmit G, Schmitz S (2014) Hydrous mantle transition zone indicated by ringwoodite included within diamond. Nature 507:221-224

Stachel T, Harris J (2008) The origin of cratonic diamonds - constraints from mineral inclusions. Ore Geology Reviews 34:5-32 